\title{
IMPLIKASI KETERAMPILAN ABAD 21 PADA PROSES PENDIDIKAN AGAMA HINDU
}

\author{
Oleh \\ I Made Dwi Susila Adnyana; Kadek Aria Prima Dewi PF \\ ringofdevilbali@gmail.com; primadewipf@ihdn.ac.id \\ Kementerian Agama Kantor Wilayah Provinsi Bali Indonesia; Institut Hindu Dharma Negeri \\ Denpasar, Indonesia \\ diterima 15 Agustus 2019, direvisi 19 September 2019, diterbitkan 1 Oktober 2019
}

\begin{abstract}
Technological developments today's have entered a global level and cover all fields including education. To face the challenges of the future, Human Resources must be improved, so compulsory education is a top priority. In relation to Hinduism education, the teacher as an educator must absolutely be able to develop 21st century skills, as stated in the 2013 Curriculum implementation, so that students are able to realize it when they enter the community. The implications of 21 st century skills in the process of Hinduism education actually expect that Hindu students as the next generation of Hindus in the future, are able to think critically to break down irrelevant dogmas. 21st century skills also emphasize improving social and spiritual attitudes that are able to realize Hindu students care for others, care for the environment, and have strong sradha and bhakti. In addition, 21st century skills also expect Hindu students to have online-based work skills and readiness to compete globally. Thus, Hindu's students as the next generation of young people will be able to face the challenges of the future in the future with strong human resources and also have great spiritual mentality.
\end{abstract}

Keywords: 21st Century Skills, Hindu Religion Education.

\begin{abstract}
ABSTRAK
Perkembangan teknologi dewasa ini sudah memasuki taraf global dan mencakup kesegala bidang termasuk bidang pendidikan. Untuk menghadapi tantangan masa depan, Sumber Daya Manusia (SDM) harus ditingkatkan, sehingga pendidikan wajib menjadi suatu prioritas utama. Dalam kaitannya dengan pendidikan agama Hindu, guru selaku pendidik, mutlak harus mampu mengembangkan keterampilan abad 21, sebagaimana yang tertera dalam implementasi Kurikulum 2013, sehingga siswa mampu merealisasikannya ketika terjun di lingkungan masyarakat. Implikasi dari pada keterampilan abad 21 dalam proses pendidikan agama Hindu sesungguhnya mengharapkan agar siswa Hindu sebagai generasi penerus Hindu dimasa mendatang, mampu untuk berpikir kritis untuk mendobrak dogmadogma yang tidak relevan. Keterampilan abad 21 juga menekankan pada peningkatan sikap sosial dan spiritual yang mampu mewujudkan siswa Hindu peduli terhadap sesama, peduli terhadap lingkungan, serta memiliki sradha dan bhakti yang kuat. Selain itu, keterampilan abad 21 juga mengharapkan siswa Hindu, agar memiliki kemampuan dan kesiapan kerja berbasis online untuk dapat bersaing ditingkat global. Dengan demikian, siswa Hindu sebagai generasi muda penerus bangsa, akan mampu menghadapi tantangan zaman dimasa mendatang dengan SDM yang kuat dan juga memiliki mental spiritual yang hebat.
\end{abstract}

Kata kunci : Keterampilan Abad 21, Pedidikan Agama Hindu. 
ADI WIDYA: Jurnal Pendidikan Dasar

FAKULTAS DHARMA ACARYA

INSTITUT HINDU DHARMA NEGERI
Volume. 4, Nomor 2 Oktober 2019

ISSN: 2685-8312 (online)

ISSN: 2527-5445 (cetak

http://ejournal.ihdn.ac.id/index.php/AW

\section{PENDAHULUAN}

Memasuki era teknologi digital, segala sesuatu kini serba berbasis online. Kehidupan manusia semua didasari dengan jaringan internet, mulai dari aplikasi sederhana hingga pada aplikasi yang canggih. Hal ini dapat di lihat melalui penggunaan ojek online, pembayaran online, absensi online, hingga aplikasiaplikasi online lainnya. Andi (2018) menyatakan bahwa abad ke-21 ini dinamakan sebagai era Revolusi Industri 4.0. Andi menjelaskan bahwa dalam Revolusi Industri 4.0 tersebut lahir manakalah dicetuskan dalam World Economic Forum (WEF) tahun 2015 oleh Kanselir Jerman yang bernama Angela Merkel. Revolusi Industri 4.0 ditandai dengan adanya pengunaan kecerdasan buatan (Artificial Intelligence), produkproduk hasil dari Nanotechnology dan Biotechnology, kendaraan tanpa awak (Autonomous Vehicles), 3-D Printing, pabrik-pabrik mengadopsi The Internet of Things (IoT), Energy Storage, dan Quantum Computing. Dari lahirnya Revolusi Industri 4.0 tersebut, tentu manusia harus dapat mengembangkan dan juga meningkatkan Sumber Daya Manusia (SDM), untuk menghadapi tantangan masa depan. Dalam pengembangan Sumber Daya Manusia yang unggul, tentu harus didasari dengan pendidikan yang terarah sebagai pondasi yang kuat dalam menghadapi kemajuan zaman dimasa mendatang.

Tinjauan tentang persiapan manusia untuk menghadapi tantangan masa depan, jika di lihat dari sudut pandang pendidikan sebenarnya sudah tertera dalam implementasi Kurikulum 2013, yaitu pada penyiapan generasi emas untuk sekian tahun mendatang. Menurut Kopeuw (dalam Triyono, 2016:5) menyatakan bahwa penjabaran kata "EMAS" adalah Energik, Multitalenta, Aktif, dan Spiritual yang akan terwujud pada tahun 2045 mendatang. Sebab, keadaan generasi
Indonesia akan terlihat meningkat ketika Indonesia berusia 100 tahun merdeka. Dari pernyataan tersebut, dapat di lihat bahwa aspek yang terdapat pada setiap Kompetensi Inti dalam Kurikulum 2013 mengharapkan terciptanya generasi emas untuk 27 tahun mendatang. Inilah yang diharapkan pada output Kurikulum 2013.

Penyiapan generasi emas untuk tahun 2045 dapat diterapkan melalui pengembangan keterampilan abad 21 dalam implementasi Kurikulum 2013. Susianna (2014:1) menyatakan bahwa Kurikulum 2013 merupakan kurikulum yang berbasis kompetensi, jadi bagaimana implementasi keterampilan abad 21 dalam kurikulum 2013 terletak pada setiap Kompetensi Inti yang mencakup aspek sikap spiritual dan sikap sosial, aspek keterampilan, dan aspek pengetahuan yang harus dimiliki siswa ketika terjun di lingkungan masyarakat. Dengan demikian, peran pendidikan sangat menjadi prioritas utama dalam mewujudkan generasi emas untuk menghadapi tantangan zaman pada masa mendatang. Maka dari itu, pembangunan dan pengembangan bidang pendidikan menjadi sangat penting, guna terciptanya generasi bangsa yang unggul.

\section{PEMBAHASAN}

\subsection{Pendidikan Agama Hindu}

Pendidikan secara umum, pada dasarnya adalah suatu proses untuk dapat memanusiakan manusia sebagai manusia. Apabila ditinjau secara khusus tentang pendidikan dalam agama Hindu, pendidikan tidak hanya berkiblat pada proses pemanusiaan manusia sebagai manusia saja. Namun, dalam konteks Hinduisme; pendidikan lebih menekankan pada proses pemanusian kesemua aspek kehidupan di alam semesta. Hal ini sejalan dengan konsep Tri Hita Karana dalam Hinduisme, dimana konsep ini mengajarkan tentang pengharmonisan antara manusia dengan manusia, manusia 
ADI WIDYA: Jurnal Pendidikan Dasar

FAKULTAS DHARMA ACARYA

INSTITUT HINDU DHARMA NEGERI
Volume. 4, Nomor 2 Oktober 2019

ISSN: 2685-8312 (online)

ISSN: 2527-5445 (cetak

http://ejournal.ihdn.ac.id/index.php/AW dengan alam semesta, dan manusia dengan sang pencipta. Dengan demikian, pendidikan agama Hindu dapat didefinisikan sebagai suatu proses pentransferan ilmu pengetahuan yang dilakukan oleh Guru (Acarya) selaku pemberi ilmu pengetahuan, kepada Siswa (Sisya) selaku pencari ilmu pengetahuan, agar dapat mewujudkan suatu keharmonisan di dalam dunia ini.

Pendidikan dalam Hinduisme sesungguhnya sudah diterapkan sejak zaman dahulu, bahkan sebelum lahirnya pendidikan di dunia Barat. Hal ini sangat relevan dan bukan suatu pernyataan apologis belaka. Sebab, Hinduisme merupakan agama tertua di dunia. Donder (2006:23) menyatakan bahwa sistem pendidikan dalam agama Hindu sudah diterapkan sejak zaman dahulu, dimana sistem pendidikan ini dinamakan dengan sistem Parampara, yang mengandung arti duduk dekat kaki guru. Bahkan penyampaian ajaran Weda-pun dilaksanakan secara lisan melalui tradisi Parampara ini. Dalam sistem Parampara ini, etika berguru sangat ditekankan, dalam artian bahwa siswa yang ingin belajar harus berdisiplin dan patuh terhadap perintah guru, karena gurulah yang akan memberikan ilmu pengetahuan kepada siswa, supaya terhindar dari belenggu kebodohan. Lebih lanjut dinyatakan oleh Donder (2008:111), guru sesungguhnya merupakan perwujudan dari tuhan, karena kata "GURU" merupakan singkatan dari Gunatitha Rupavrjitha, yang mengandung arti 'orang yang tidak terbelenggu oleh materi dan dapat menyeberangkan orang lain dari lautan sengsara'. Dengan kata lain, sosok yang tak terbelenggu materi dan mampu menyeberankan orang lain dari lautan sengsara ialah perwujudan Tuhan. Jadi, sangat jelas sekali bahwasannya implementasi dari pada pendidikan agama Hindu telah terlaksana sejak ribuan tahun lalu, dimana sistem pendidikan tersebut diberi nama dengan sistem Parampara. Tujuan dari sistem Parampara ini juga sangat tepat apabila dikaitkan dengan tujuan pendidikan nasional, yatu menciptakan siswa yang berilmu pengetahuan tinggi, namun juga memiliki moralitas yang baik, beretika, berdisiplin, bertaqwa kepada Tuhan Yang Maha Esa, serta berbudi pekerti yang luhur.

\subsection{Keterampilan Abad 21}

Abad 21 merupakan era dimana teknologi menjadi basis kehidupan manusia. Semua kegiatan manusia dilakukan secara online, dengan kata lain segala sesuatu dilakukan menggunakan jaringan internet. Hal semacam ini menyebabkan sebuah tantang disegala bidang, khususnya pada bidang pendidikan. Dalam implementasi Kurikulum 2013, terdapat empat Kompetensi Inti yang saling terkait satu sama lain sehingga akan melahirkan keterampilan abad 21 yang disiapkan bagi siswa untuk menghadapi tantangan zaman dimasa mendatang. Siti (2016:15) menyatakan bahwa keterampilan abad 21 merupakan keterampilan yang perlu diberikan kepada siswa guna mempersiapkan lulusan yang mampu untuk bekerja menjadi warga negara yang baik dan mampu menghadapi pengaruh globalisasi, kemajuan teknologi, kompetisi internasional, perubahan pasar global, lingkungan transnasional dan perubahan politik, agar siswa semakin maju dimasa mendatang. Dari paparan tersebut, sudah seharusnya guru selaku pendidik, mampu mengembangkan dan menerapkan sebagaimana apa yang disebut keterampilan abad 21 untuk mewujudkan siswa yang ber-SDM tinggi, dan mampu bersaing secara global.

Wagner (2014) dalam bukunya yang berjudul "The Global Achievement Gap" mengatakan bahwa untuk mendukung paradigma baru pembelajaran abad 21, guru perlu mengembangkan 4C kepada 
siswa, agar nantinya siswa dapat berkembang lebih maju. 4C tersebut adalah Critical Thinking, Collaboration, Communication, dan Creativity. Yang diharapkan dari pengembangan 4C tersebut, adalah untuk mewujudkan siswa yang mampu berfikir kritis, mampu untuk berkolaborasi, mampu berkomunikasi multi arah, dan juga mampu mengembangkan kreatifitas. Di dalam mengembangkan 4C tersebut (Critical Thinking, Collaboration, Communication, Creativity), guru selaku pendidik harus mampu mengetahui setiap kemampuan siswa. Maka dari, guru perlu memahami apa yang namanya Self Assessment, atau dengan kata lain 'Penilaian Diri' kepada setiap siswa. Warner (2016) menyatakan bahwa pada fase Critical Thinking, guru harus mampu menilai sejauh mana kemampian siswa dapat berfikir secara fundamental, dalam artian apakah siswa tersebut sudah mampu berfikir secara mendasar, kritis, dan logis. Kemudian pada fase Collaboration, guru harus mengetahui sejauh mana kemampuan siswa untuk bisa berkolaborasi bersama teman sejawat dalam suatu team work. Pada fase ini, diharapkan agar siswa mampu membuka jaringan sosial di dunia kerja nantinya. Selanjutnya pada fase Communication, guru harus mampu mengetahui sejauh mana siswa tersebut dapat memfilter informasi yang didapat melalui jejaring sosial media, karena munculnya berita hoax akan dewasa ini akan memicu komunikasi anatara siswa dan lingkungan sekitar dapat terganggu. Fase terakhir yaitu Creativity, diharapkan guru mampu mengukur tingkat kreativitas siswa di dalam mengembangkan kemampuan dan keterampilannya pada penggunaan media berbasis online.

Uraian tentang pengembangan keterampilan abad 21 melalui fase $4 \mathrm{C}$ tersebut dengan menggunakan metode Self Assessment (Penilaian Diri) terhadap siswa, apabila dikorelasikan terhadap proses pendidikan agama Hindu dan kemudian dibuatkan gambar sederhana akan terlihat sebagai berikut:

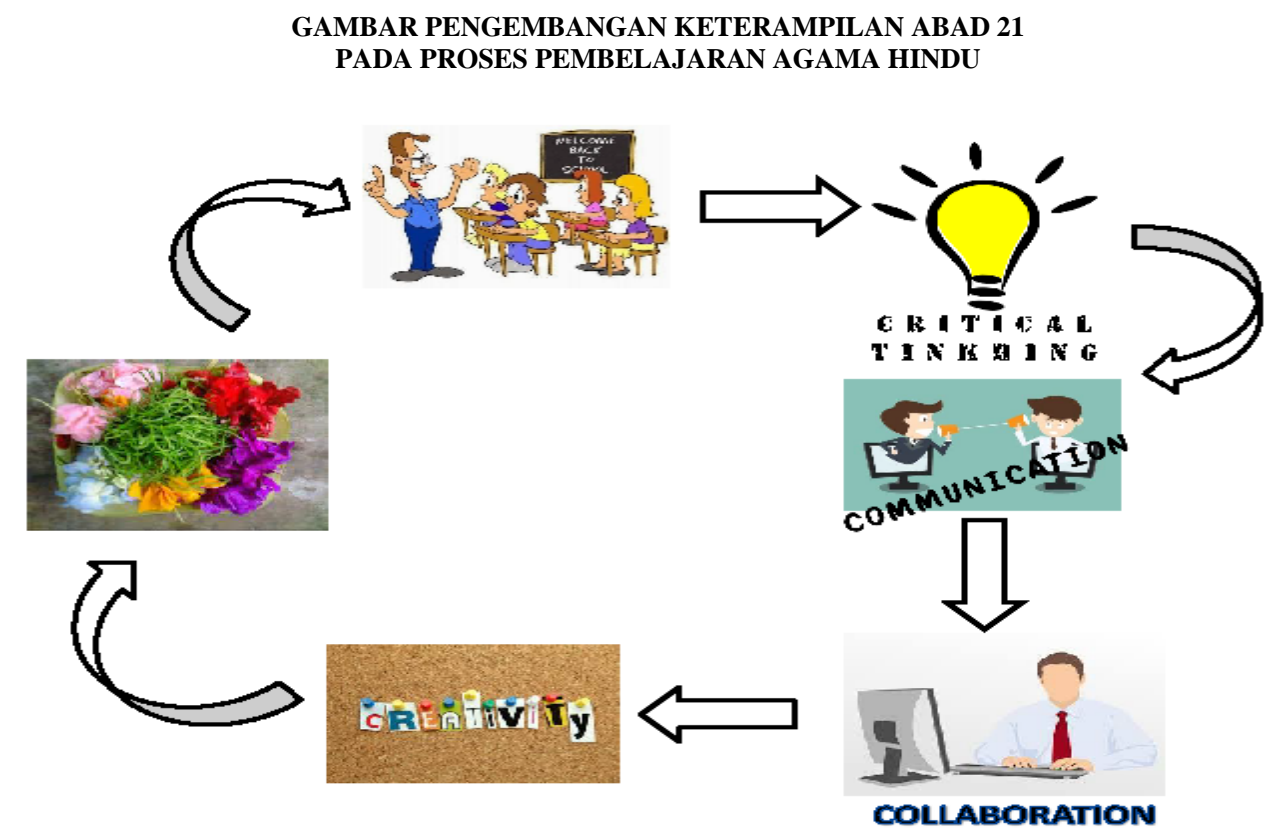

Penjelasan tentang gambar di atas adalah ketika guru memberikan pemahaman kepada siswa tentang pentingnya keterampilan abad 21 (Critical Thinking, Collaboration, Communication, Creativity) melalui contoh canang sari, 
Critical Thinking (berpikir kristis) akan menjadikan siswa untuk dapat berpikir secara logis dan mendasar tentang makna canang sari tersebut. Apabila siswa telah memahami makna dari pada canang sari tersebut, maka siswa akan dapat menjelaskan filosofi canang sari tersebut secara mendasar, sehingga siswa tidak hanya tau bentuk dan fungsi canang sari tersebut, akan tetapi juga memahami maknanya. Setelah siswa memahami makna dari pada canang sari tersebut, siswa akan mampu mengkomunikasikan (Communication) kepada setiap orang yang bertanya tentang apa arti canang sari tersebut. Setelah pengkomunikasian, siswa akan dapat mengkolaborasikan (Collaboration) kepada kolega atau teman sejawat, yang nantinya akan berfungsi sebagai kerja sama tim (team work) untuk menjadikan canang sari sebagai peluang bisnis yang berbasis online. Hal ini dapat menjadi sebuah kreativitas yang akan dapat dikembang secara komprehensif untuk dapat meningkatkan persaingan di dunia kerja yang berbasis online. Agar memahami lebih jelas lagi implikasi keterampilan abad 21 pada proses pendidikan agama Hindu sebagaimana yang dijelaskan di atas, akan diuraikan pada sub-sub di bawah ini.

\subsubsection{Critical Thinking}

Critcal Thinking berarti berpikir kritis, dalam artian merupakan suatu pemikiran yang logis dan mendasar. Dalam fase Critical Thinking ini, siswa diharapkan mampu untuk berfikir secara logis dan mendasar guna mendobrak adanya dogmadogma yang kurang relevan di era sekarang dan mendatang, serta mencari makna yang dapat dijelaskan berdasarkan logika. Dengan demikian, akan terciptanya siswa Hindu yang berkualitas dan meningkatkan mutu pendidikan agama Hindu berlandaskan pemikiran yang logis dan mendasar.

\subsubsection{Communication}

Komunikasi (Communication) adalah suatu penerapan kemampuan siswa untuk dapat berkomunikasi secara multi arah. Tujuan siswa untuk dapat berkomunikasi multi arah, mengharapkan siswa untuk dapat menjelaskan tentang apa yang terdapat dalam Hinduisme supaya dipahami oleh setiap orang yang ingin mengetahui Hinduisme secara mendalam. Hal ini disebabkan oleh masuknya pengaruh globalisasi serta budaya asing yang akan menjadikan siswa Hindu harus mampu berkomunikasi secara multi arah. Jadi, peningkatan kualitas pendidikan agama Hindu akan terus berkembang melalui komunikasi yang multi arah.

\subsubsection{Collaboration}

\section{Kolaborasi}

(Collaboration) merupakan suatu rancangan untuk dapat mengembangkan kerja sama tim (team work) kepada siswa Hindu yang nantinya dijadikan sebagai acuan untuk dapat bersaing secara global di tengah arus globalisasi dan teknologi yang semakin berkembang. Dari adanya suatu kolaborasi yang efektif, maka akan terwujudnya daya saing siswa Hindu yang semakin meluas, terutama dalam mengahadapi tantangan global.

\subsubsection{Creativity}

Kreatifitas (Creativity) merupakan implikasi dari pada keterampilan abad 21 yang bertujuan untuk mewujudkan siswa Hindu yang berkreatifitas tinggi. Melalui kreatifitas yang tinggi, siswa Hindu diharapkan mampu mengembangkan keterampilan yang terus menurus sehingga keterampilan yang ada pada siswa Hindu semakin terus meningkat. Dengan terciptanya siswa Hindu yang kreatif, maka akan dapat mengembangkan kreativitas di bidang seni dan budaya berlandaskan budaya setempat (loacal genius). 


\section{KESIMPULAN}

Implikasi keterampilan abad 21 dalam proses pendidikan agama Hindu sesungguhnya bertujuan untuk menyiapkan siswa Hindu yang mampu berpikir secara kritis dan logis, agar dapat mendobrak dogma-dogma yang tidak relevan lagi dimasa kini, serta mampu menjelaskan bagaiman filosopi dari pada ajaran agama Hindu tersebut berdasarkan logika (Critical Thinking). Siswa Hindu juga diharapkan mampu berkomunikasi secara multi arah kepada setiap orang yang datang, sebab dewasa ini merupakan kehidupan yang transnasional (Communication). Selain itu, siswa Hindu juga diharapkan untuk dapat mengkolaborasikan suatu kebudayaan setempat dengan tuntutan pasar yang berbasis online (Collaboration), sehingga keterampilan sangat diperlukan untuk mewujudkan terciptanya perihal tersebut (Creativity). Dengan demikian, melalui keterampilan abad 21 yang diimplementasikan oleh guru kepada siswa, mengharapkan agar terwujudnya siswa Hindu yang cerdas, aktif, kreatif, dan inovatif, dengan tujuan supaya siswa Hindu mampu bersaing secara global yang didasari dengan pengetahuan mulia, sehingga kehidupan di alam semesta ini tetap terjaga secara harmonis.

\section{DAFTAR PUSTAKA}

Andi Nur, B. M. (2018). Making Indonesia 4.0, Babak Baru Industri Kita. Makasar: Artikel Harian Fajar Edisi 12 April 2018.

Donder, I. K. (2006). Sisya Sista:

Pedoman Menjadi Siswa Mulia. Surabaya: Paramita.
Donder, I. K. (2008). Acarya Sista: Guru

\& Dosen yang Bijaksana. Surabaya:

Paramita.

Siti, Z. (2016). Keterampilan Abad Ke-21: Keterampilan yang Diajarkan Melalui Pembelajaran. Universitas Negeri Malang. (Online). Tersedia di:

https://scholar.google.co.id/citation s? user=IpsUUUIAAAAJ \&hl=id\#d =gs_md_cita$\mathrm{d} \& \mathrm{p}=\& \mathrm{u}=\% 2$ Fcitations\%3Fview_o p\%3Dview_citation\%26hl\%3Did\% 26user\%3DIpsUUUIAAAAJ\%26ci tation_for_view\%3DIpsUUUIAAA AJ\%3AX16nMS1579sC\%26tzom\% 3D-420. (Diakses Tanggal 12 Desember 2018)

Susiana, N. (2014). Implementasi Keterampilan Abad 21 dalam Kurikulum 2013. STKIP SURYA: Proceeding Seminar Nasional.

Triyono. (2016). Menyiapkan Generasi Emas 2045. Universitas Widya Dharma Klaten: Prosiding Active Learning Facilitatar Assoclation (ALFA) IV.

Wagner, T. (2014). The Global Achievement Gap: Why Even Our Best Schools Don't Teach The New Survival Skills Our Children Need And What We Can Do About It. New York: Basic Book.

Warren, A. (2016). Project-Based Learning Across The Disciplines: Plan, Manage, and Assess Through +1 Pedagogy. California: Corwin Press Inc. 